\title{
Article \\ Failure Analysis of Some Commercial Spotlights Based on Light Emitting Diodes
}

\author{
Wei Zhong and Thomas Walther *(D) \\ Department of Electronic \& Electrical Engineering, University of Sheffield, Mappin Building, Mappin Street, \\ Sheffield S1 3JD, UK; wzhong7@sheffield.ac.uk \\ * Correspondence: t.walther@sheffield.ac.uk
}

check for updates

Citation: Zhong, W.; Walther, T. Failure Analysis of Some Commercial Spotlights Based on Light Emitting Diodes. Electronics 2022, 11, 48. https://doi.org/10.3390/ electronics11010048

Academic Editor: Ilgu Yun

Received: 19 November 2021

Accepted: 21 December 2021

Published: 24 December 2021

Publisher's Note: MDPI stays neutral with regard to jurisdictional claims in published maps and institutional affiliations.

Copyright: () 2021 by the authors. Licensee MDPI, Basel, Switzerland. This article is an open access article distributed under the terms and conditions of the Creative Commons Attribution (CC BY) license (https:// creativecommons.org/licenses/by/ $4.0 /)$.

\begin{abstract}
The failure mechanism of two commercial light-emitting diode (LED)-based spotlights with GU10 form factor is analyzed. Through component testing and comparison to nominal values as well as to simulations, it is found that the cause of both device failures is related to damaged components within the drive circuits rather than the LEDs themselves. Both LED heads work as normal when connected to an external direct current (DC) source. The results show that the lack of light output of one spotlight is related to the open circuit caused by damaged resistors and inductors in its drive circuit, while the flickering of the other is related to the malfunction of the integrated circuit providing constant current output. Therefore, improving the quality of the LED drive circuits is considered the most effective way for manufacturers to reduce catastrophic failures of LED spotlights.
\end{abstract}

Keywords: drive circuit; light-emitting diode (LED); spotlight; LED head; failure analysis; lifetime

\section{Introduction}

The light-emitting diodes (LEDs) enable solid state lighting that is more energyefficient than incandescent and fluorescent lamps [1,2]. With the awareness for the necessity to reduce electrical energy consumption, LED-based solid state lighting is increasingly being used in people's homes, gradually replacing traditional incandescent and fluorescent lamps. Spotlights based on the GU10 form factor, as shown in Figure 1, are very compact luminaires and can be integrated in many lamp geometries.

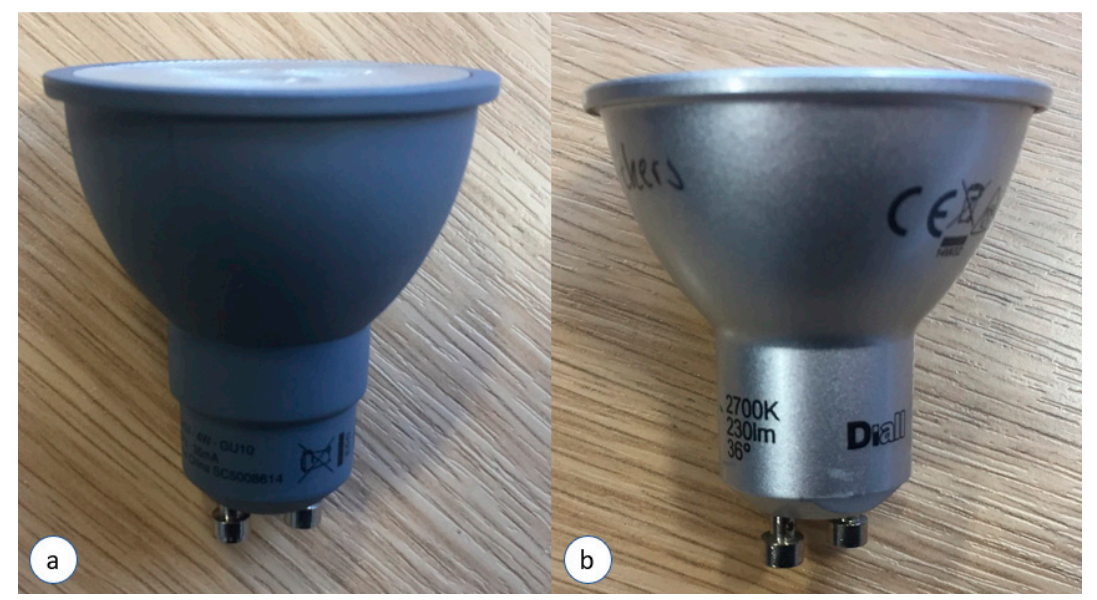

Figure 1. Two failed LED spotlights with GU10 socket. Sample A (a) does no longer emit any light, Sample B (b) flickers.

LEDs went through a long period of development before they entered the lighting market. In 1907, Round observed the photoluminescence phenomenon for the first time, and people began research on various luminous devices [3]. In 1962, Holonyak invented 
the first visible light LED, after which LED manufacture moved from the laboratory to the application field [4]. In 1993, high-brightness blue LEDs were manufactured by Nakamura at Nichia, so that LEDs were able to enter the commercial display industry [5]. After 2000, the technology of producing white light by combining blue LEDs with yellow phosphor coatings began to appear [6]. Since then, commercial LED lighting has entered the consumer market. Nowadays, white LED based lamps are an important part of the lighting industry, promising long life and energy-savings for a wide range of applications, both of which justify a premium resale price. Manufacturers advertise lifetimes up to 15,000 h; however, scientific estimates cover a wide range from only $5000 \mathrm{~h}$ [7] over 25,000 h [8] up to $100,000 \mathrm{~h}$ [9]. It is clear that overall system reliability will depend on the lifetime of the weakest link in the conversion chain from electricity to light. Several different modes of thermo-mechanical failure in solid state lighting systems have been identified that can lead to either gradual reduction of light output (mainly due to ageing of the encapsulating phosphor) or to sudden failure in the form of cracking (of encapsulation or of solder joints) or bond delamination (between die/encapsulation, die/adhesive or support/thermal interface materials) [10]. We have examined several failed commercial LED spotlights and here report results from two such samples that showed two different common signs of catastrophic system failures. These luminaires with GU10 form factor are more compact than those with E27 screw caps for which infrared thermography identified the metal vias within the LEDs and the soldered interconnects to the drive electronics boards as the thermally most stressed, and hence possibly weakest, parts [11].

The principle of LEDs relies on spontaneous emission, generated by recombination of electrons and holes in the pn-junction of a semiconductor [12]. In the diode, free electrons are transported into the depletion region under forward bias where the electrons recombine with holes and spontaneous emission of photons occurs. Therefore, a direct constant (DC) current source is necessary for an LED [13].

This study analyzes the causes of failures of two commercial GU10 LED lights by testing all their electric components and simulating the behaviour of the electric drive units whose internal integrity cannot be checked directly. The two devices studied in detail are shown in Figure 1. One of them (Sample A) does not produce any light output anymore while the other one (Sample B) reveals a strong visible flicker. Both types of catastrophic failure modes occurred within 2 years of installation ( $<2000 \mathrm{~h}$ of operation) and are commonly found in solid-state lighting, along with more gradual degradation in the form of a decrease of emission intensity or chromatic shifts with time both of which can be studied by accelerated ageing at high temperatures either in quality control type experiments [14-16] or by corresponding lifetime prediction modelling [17-19].

The basic product information of both LED spotlights, in the following called samples A and B, is shown in Table 1. For testing, the two devices have been disassembled in the laboratory. Multimeters, oscilloscopes and LCR meters have been used to identify specific electrical components that had failed.

Table 1. Product information in the two LED spotlights investigated.

\begin{tabular}{ccc}
\hline Criterion & Sample A & Sample B \\
\hline Manufacturer & unknown & Diall \\
Failure type & no light output & flickering \\
Input voltage & $220-240 \mathrm{~V} \mathrm{AC}$ & $220-240 \mathrm{~V} \mathrm{AC}$ \\
Rated working current & $35 \mathrm{~mA}$ & $44 \mathrm{~mA}$ \\
Power consumption & $4 \mathrm{~W}$ & $4.5 \mathrm{~W}$ \\
Nominal brightness & $230 \mathrm{~lm}$ & $230 \mathrm{~lm}$ \\
Frequency & $50 \mathrm{~Hz}$ & $50 \mathrm{~Hz}$ \\
\hline
\end{tabular}

The LED spotlights studied in this project belong to energy-saving low-power lighting fixtures that can be used in various indoor environments. Their future market development prospects are stronger than for incandescent or fluorescent lamps [20] so LED lighting may 
gradually become the mainstream of the lighting market. Therefore, failure testing of LED lighting will also become more important for manufacturers to guarantee quality control.

\section{Methodology}

In order to analyze the cause of LED spotlight failures, the devices needed to be disassembled. The structure of GU10 LED spotlights can be divided into five parts that can be separated: optics, LED head, heat sink, drive circuit, and socket. The functional description of each part is shown in Table 2. The optics, the heat sink, and the socket base do not involve any electrical components and their integrity can be easily confirmed by visual inspection. Most drive circuits are designed to operate at 220-240 V AC. All simulations are performed for $240 \mathrm{~V}$, while experiments refer to the $230 \mathrm{~V} 50 \mathrm{~Hz}$ grid used in the UK or to the actual voltages applied.

Table 2. Functions of each part of the LED spotlights.

\begin{tabular}{cc}
\hline Part Name & Function \\
\hline Optics & Guide light from LED head to yield even illumination \\
LED head & Light-emitting part of the device, usually composed of \\
multiple sets of single LEDs
\end{tabular}

The LED head and drive circuit are the key parts for electrical testing. When testing these two parts, the isolated LED head is tested first. If it works and is not faulty, then the LED drive circuit must be at fault and is tested. The following will introduce the test methods of these two parts and the theory that has been used.

\section{Component Analysis}

\subsection{LED Heads}

Photos of both LED heads are shown in Figure 2. There are three pairs of LEDs on each lamp panel, and two LEDs in each pair. Therefore, there are six individual LEDs for each base panel. Besides, two resistors are connected in parallel on the panel of Sample B. These resistors are designed to keep the voltage stable without load. Sample A also has a resistor in parallel with the LED head at the output but this is located on the drive circuit board.

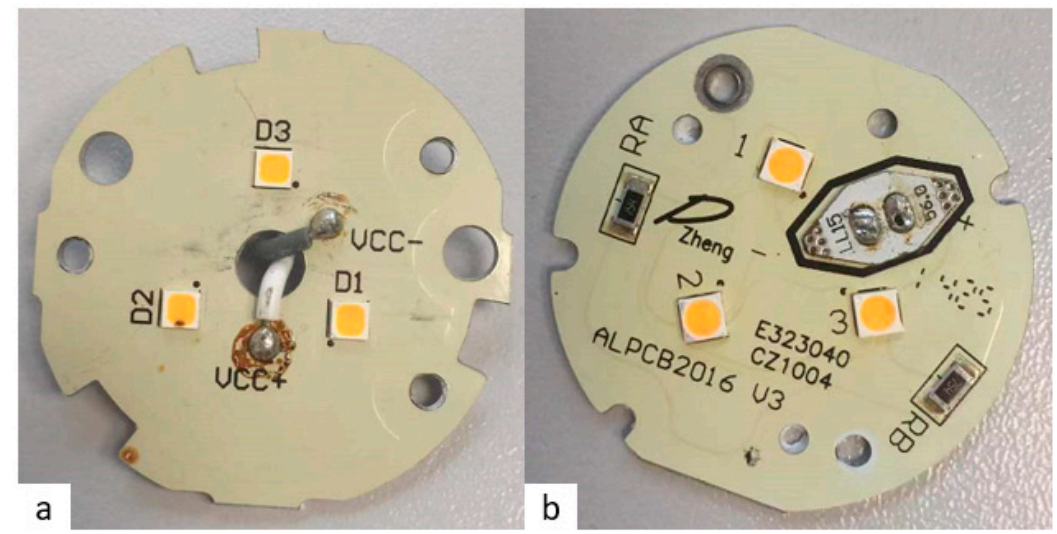

Figure 2. Photographs of LED heads of the spotlights from Samples A (a) and B (b).

LEDs are unidirectional conductive devices. Therefore, in order to test the two LED heads, it is necessary to supply DC voltage to them. The test circuit used consists of a power supply, an ammeter and the LED head to be tested. During the test, the DC voltage 
is increased from 0 to its rated value. When the current, $I$, reaches the rated value, the voltage should he held and its value, $V$, is recorded. Which LEDs light up is noted. After the measurement is completed, the forward resistance of the entire LED head circuit can be calculated from Ohm's law.

If the LED head is not illuminating, due to the series connection of all the LEDs, it can be concluded that at least one LED or the resistors in parallel must be damaged. Then each LED pair should be unsoldered from the LED heads and be tested individually to identify the damaged LEDs.

\subsection{LED Drive Circuits}

The LED drive circuit is another important part of the LED lamp structure. For protection, the packaging of the drive circuit is often sealed by the manufacturer, and some products are additionally internally encapsulated by silicone for further protection (such as Sample B); it is thus not easy to take out the circuits from the packaged products. In order to isolate the drive circuits shown in Figure 3, the packaging (casing, silicone, socket) had to be carefully removed by mechanical means.

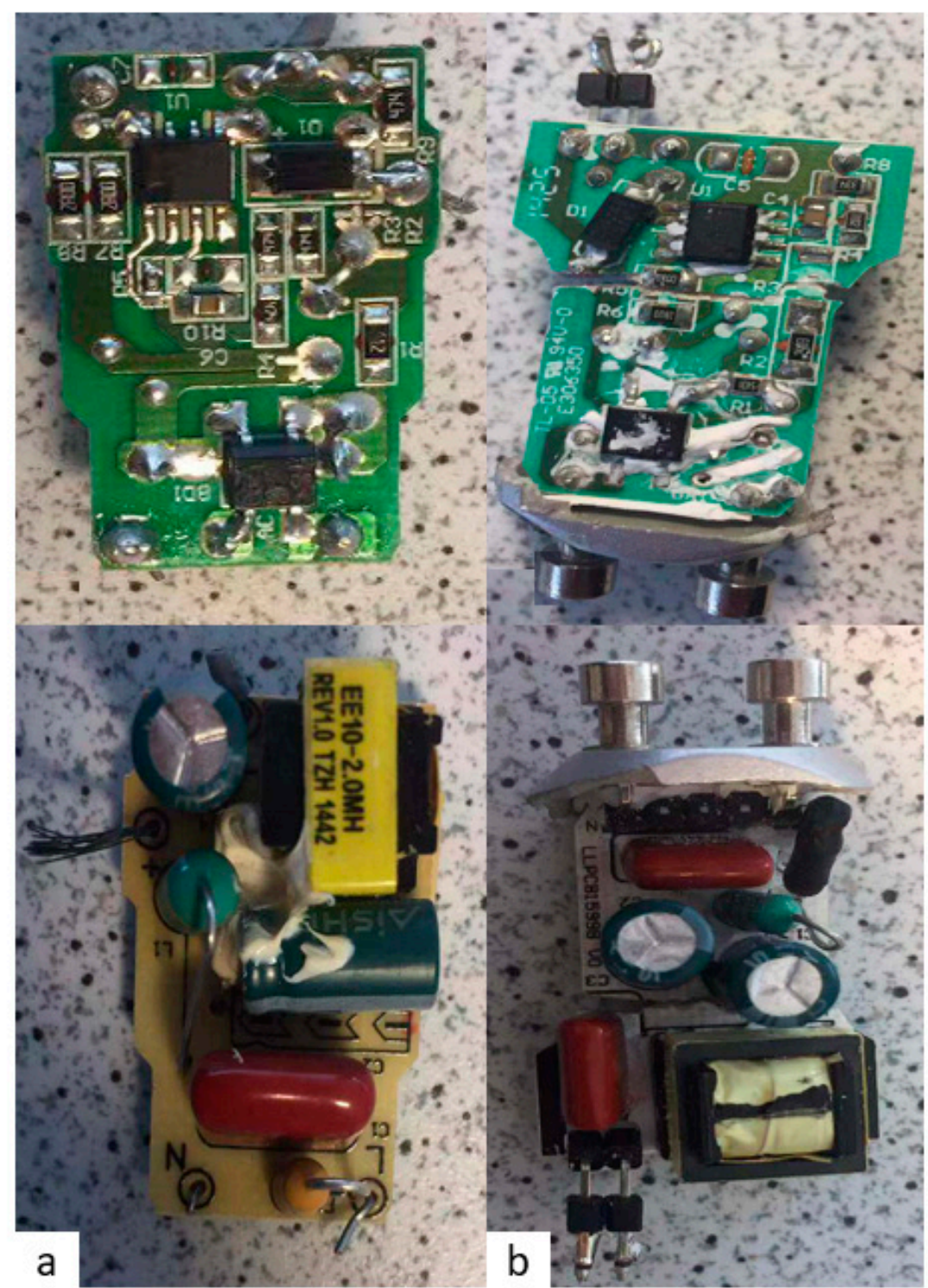

Figure 3. The two sides of both drive circuits after disassembly. Circuit boards of sample A on the left (a) and sample B on the right (b); top row: sides with tracks and ICs, bottom row: sides with discrete electrical components. 
As can be seen in Figure 3, the printed circuit board of the drive unit of Sample B cracked during disassembly. For safety reasons, we did not directly apply $230 \mathrm{~V}$ AC to test the drive circuits. In the UK, Guidance Note GS38 by the Health and Safety Executive states that all electrical testing and fault finding must not be conducted on live systems if it can be conducted otherwise and that voltages below $50 \mathrm{~V}$ AC reduce the risk of electric shock to a low level. Therefore, instead of directly applying $230 \mathrm{~V} \mathrm{AC}$ mains voltage to any point, both circuits were disassembled into their components to be tested separately. These two drive circuits are very similar. Their working principle is to convert 220-240 V AC into a stable small direct current (not real DC, but a high-frequency uni-polar triangular wave). Both circuits are composed of a bridge rectifier, a filter circuit, and a DC current control circuit, sketched in Figure 4. The test methods differ for different parts.

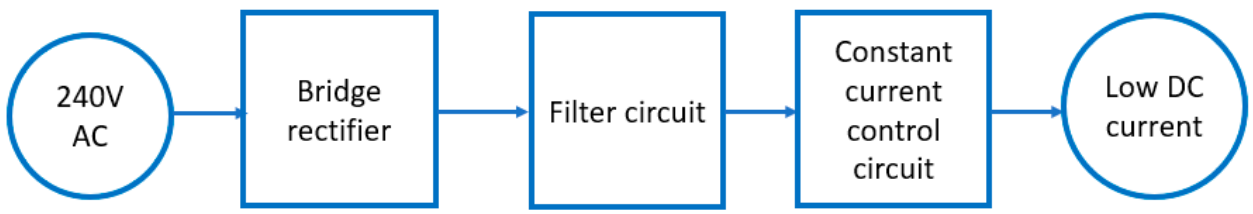

Figure 4. Schematic of the working principle of the LED drive circuit.

\subsubsection{Bridge Rectifier}

A bridge rectifier is a four-port device that typically consists of four diodes, as shown in Figure 5. The bridge rectifier is an important part of any LED drive circuit, which is used for converting $\mathrm{AC}$ to $\mathrm{DC}$ voltage by inverting the current flow during the negative half-wave to the forward direction [21]. Due to the uni-directional conductivity of a diode, diodes $D_{1}$ and $D_{3}$ allow the forward current to pass, while diodes $D_{2}$ and $D_{4}$ allow the reverse current to pass, and the final current is the sum of both. The way to test the rectifier bridge is to measure the conduction state of each of the four diodes separately by a multimeter. If one of the diodes is broken, the rectifier bridge is faulty and does not work [22].

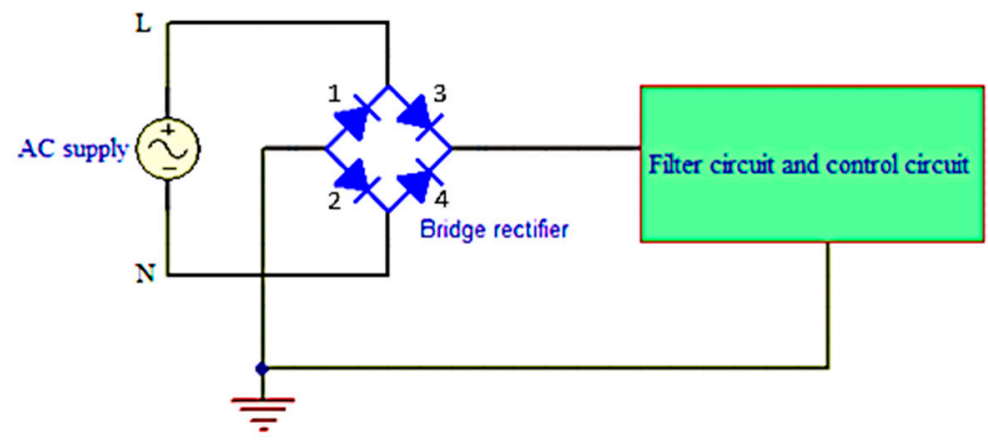

Figure 5. Principle of the bridge rectifier in an LED drive circuit. Numbers 1-4 denote diodes $\mathrm{D}_{1}-\mathrm{D}_{4}$.

\subsubsection{Filter Circuit}

The rectified voltage signal will then pass through a filter line consisting of a simple low-pass LCR circuit to obtain a stable DC signal. Shown in Figure 6 is the filter circuit for Sample A. The inductor is used to block the high frequency components of the rectified signal, which the decoupling capacitors pass to ground. Since the inductor generates an induced current when switching, a protective resistor is needed to provide a bleed path for the induced current of the inductor to protect other circuit components. Therefore, the resistor $R_{1}$ in parallel to inductor $L_{1}$ in Figure 6 acts as a protection in the circuit [23]. 


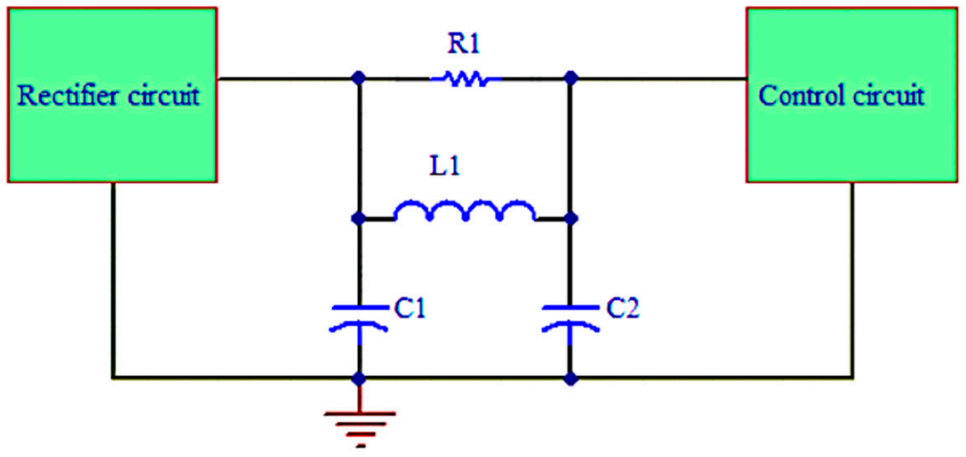

Figure 6. Filter circuit in the LED drive circuit (Sample A).

In order to verify whether resistors, inductors, and capacitors are intact in the filter circuit, a multimeter and an RLC meter are necessary. The whole rectifier and filter circuit cannot be tested with $230 \mathrm{~V}$ AC voltage in the laboratory. Therefore, it is necessary to use computer software to establish a simulation model for the rectifier and filter circuits, and to compare the component parameters for the nominal and the experimentally measured values in the model to observe whether the output result changes. If there is no significant change, it means that the deviation of the component parameters from the nominal values does not have a significant impact on the circuit.

\subsubsection{Control Circuit}

The constant current control circuit is the core part of the LED drive circuit, as shown in Figure 7 (taking Sample A as an example). The control circuit is a buck circuit controlled by a constant current integrated chip (IC). This IC, BP2831A, has eight pins. GND is the ground pin, $\mathrm{ROV}$ is the overvoltage protection pin, and the $\mathrm{NC}$ pin has no connection other than a link to GND. VCC is the power supply pin that is used to control a MOSFET inside. DRA is the drain signal. The two DRA pins are connected internally. CS is the sensing pin. The sensing resistors $\left(R_{6}\right.$ and $\left.R_{7}\right)$ need to be connected between the sensing pin and ground, and the voltage drop across the resistors will be detected by the CS terminal. $D_{1}, L_{2}, C_{3}, R_{8}$, and LED head form a buck circuit within the control circuit, whose switching states are controlled by the IC. Some specification parameters of the IC are shown in Table 3 [24].

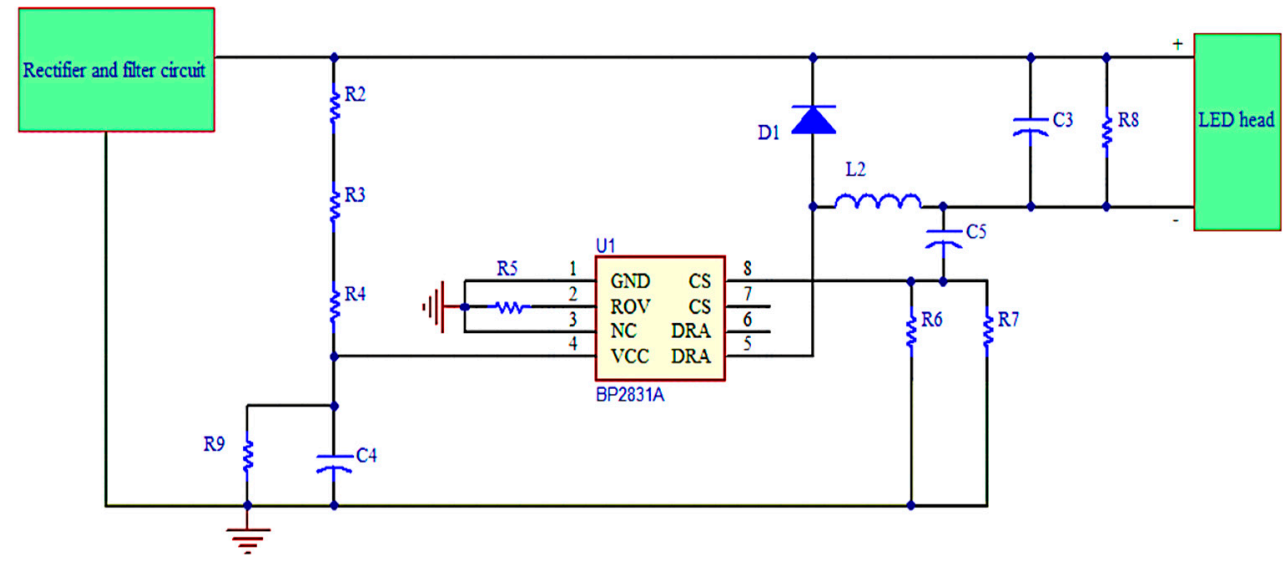

Figure 7. Current control circuit in the LED drive circuit (Sample A). 
Table 3. Specifications of IC BP2831A.

\begin{tabular}{cc}
\hline Parameter & Value \\
\hline Turn-on voltage of VCC & $13.8 \mathrm{~V}$ \\
Clamp voltage of VCC & $16.8 \mathrm{~V}$ \\
Input voltage range of circuit & 176 to $265 \mathrm{~V}$ \\
Minimum LED loading voltage & $15 \mathrm{~V}$ \\
Internal reference voltage for CS & $400 \mathrm{mV}$ \\
\hline
\end{tabular}

In the normal working state, the IC is controlled by two internal gates. One is connected to the MOSFET, which is itself controlled by the voltage of VCC. The other is a sensing circuit that is controlled by the voltage drop induced at the CS pin. For the circuit to work, the VCC terminal must be supplied with a voltage that causes the MOSFET to turn on and the CS pin must sense a voltage drop that matches the internal sensing circuit settings. The nominal turn-on voltage of VCC in the circuit of Sample A is $13.8 \mathrm{~V}$. The sensing circuit of the LED driver is set such that the induced voltage drop is less than $0.4 \mathrm{~V}$ and the gate of the sensing circuit is turned on. When the circuit is working, since the filtered voltage is DC, the voltage of VCC can be stabilized between the turn-on voltage and the clamp voltage by a series of resistors. When the MOSFET is switched on, the induced voltage drop of the CS terminal is lower than $0.4 \mathrm{~V}$. At this time, the two gates in the IC are turned on, and the entire circuit constitutes a loop. The buck circuit is thus switched on. Then, due to the charging of the inductor $L_{2}$, the CS voltage drop gradually increases from 0 to $0.4 \mathrm{~V}$. Above $0.4 \mathrm{~V}$, the IC is switched off. Then, the inductor begins to discharge and the diode $D_{1}$ conducts. The buck circuit works in the switching off mode. Subsequently, the voltage drop of CS pin will decrease below $0.4 \mathrm{~V}$, and the IC will turn on again. The buck circuit formed by the IC will, in the above manner, cause the current through the inductor to fluctuate periodically with a small amplitude and at high frequency, thereby providing a nearly constant low current output for the LED circuit [25].

The peak current of the inductor can be calculated from Equation (1), where $I_{\text {peak }}$ is the peak current of the inductor and $R_{C S}$ is the resistance of the CS pin. Since the current waveform through the inductor is an approximate triangular wave, the current through the LEDs can be calculated by Equation (2), where $\left\langle I_{L E D}\right\rangle$ is the time-averaged current through the LED head

$$
\begin{gathered}
I_{\text {peak }}=\frac{400 \mathrm{mV}}{R_{C S}} \\
\left\langle I_{L E D}\right\rangle=\frac{I_{\text {peak }}}{2}
\end{gathered}
$$

The frequency of the inductor current is related to the turn-on and turn-off times of the buck circuit. According to the characteristics of the inductor, the turn-on time and turn-off time can be calculated from Equation (3) where $t_{\text {on }}$ is turn-on time, $t_{\text {off }}$ is turn-off time, $L$ is the inductance value and $V_{i n}$ is the DC voltage after the filter circuit.

$$
t_{\text {on }}=\frac{L \times I_{\text {peak }}}{V_{\text {in }}-V_{L E D}}, t_{\text {off }}=\frac{L \times I_{\text {peak }}}{V_{L E D}}
$$

From Equation (3), the relationship between the frequency and inductance can be derived, as shown in Equation (4), where $f$ is the frequency of the current through the inductor [24].

$$
L=\frac{V_{L E D} \times\left(V_{i n}-V_{L E D}\right)}{f \times I_{\text {peak }} \times V_{i n}}
$$

In order to test whether the IC is working properly, it is necessary to supply a voltage to observe the waveform on an oscilloscope. However, our simulation software library lacks detailed information on the ICs so that they can only be compared qualitatively. The measurement consists of two parts. The first part will measure the VCC of the IC directly 
and observe whether the turn-on voltage and clamp voltage are following suit as described in the manual. The test circuit diagram for VCC is shown in Figure 8. The test circuit cuts off the external circuits from the VCC pin and the drain pin, and the other pin connections are identical to the original circuit. The VCC pin is directly connected to a positive DC voltage. The waveform at the drain pin will be observed as VCC increases.

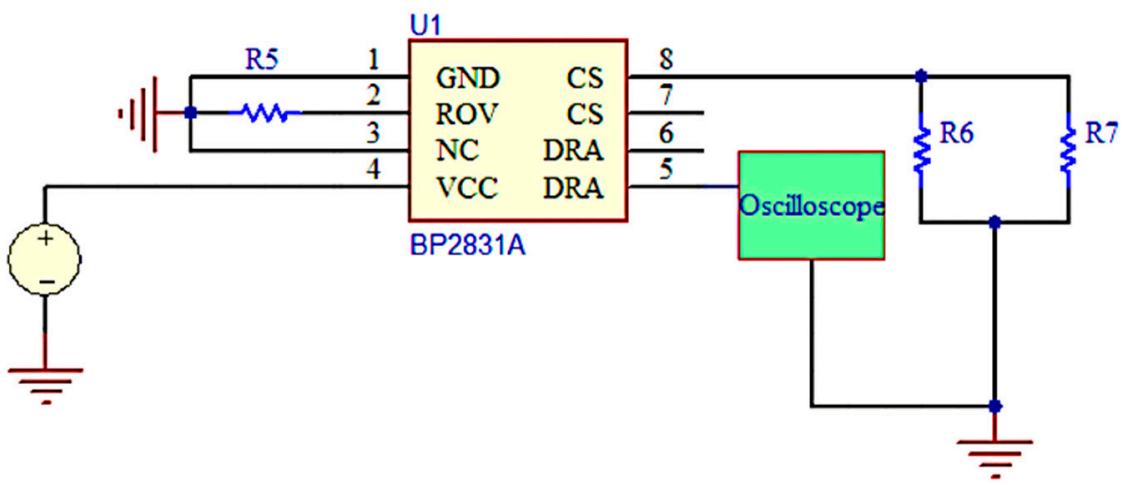

Figure 8. Test circuit of the MOSFET controlled by VCC (Sample A).

The second part is to test the modified control circuit, as shown in Figure 9. The modification method is to disconnect $R_{2}, R_{3}$, and $R_{4}$ respectively and supply power to the bus and VCC. In addition, it is necessary to replace the LED with a small resistor (as the LED forward resistance is too large to operate at an input voltage less than $40 \mathrm{~V}$ in the laboratory). The oscilloscope's dual channels are connected across the resistors to measure the input voltage and the voltage across the resistor. An ammeter is also added to the circuit. The ammeter coefficient, the waveform of the input voltage $\left(V_{\text {in }}\right)$, and the voltage waveform across the resistor $\left(V_{R}\right)$ will be observed, where $V_{i n}$ equals $V_{C H 1}$ and $V_{R}$ equals $V_{C H 1}-V_{C H 2}$. The average voltage across the resistor can be calculated by Equation (5), where $V_{p p}$ is the peak-to-peak voltage of $V_{R}$.

$$
\left\langle V_{\text {average }}\right\rangle=\frac{V_{p p}}{2}
$$

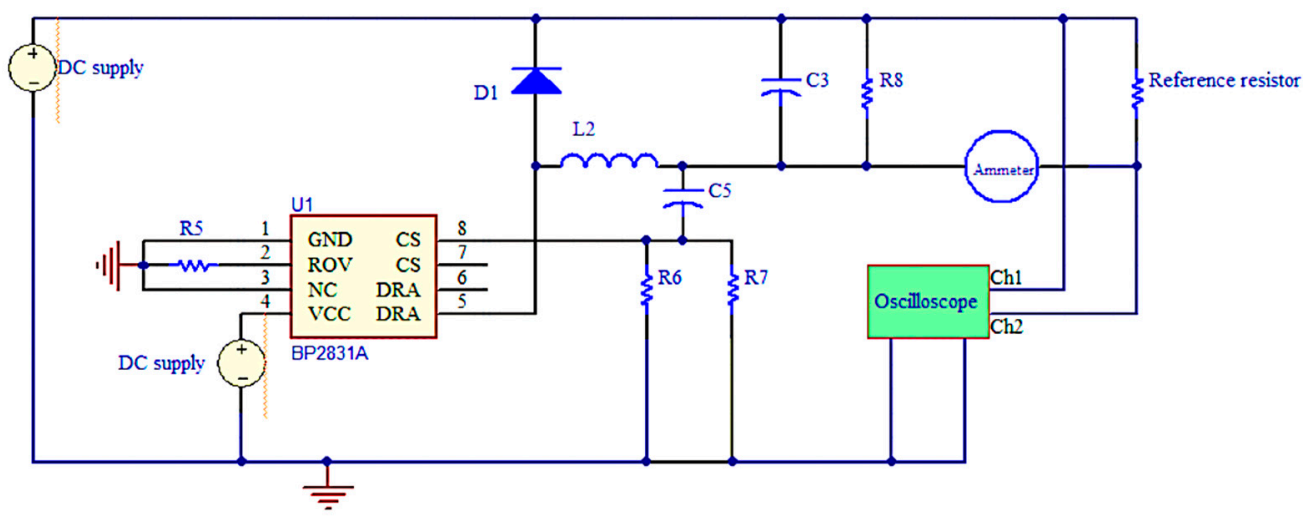

Figure 9. Test circuit of the modified control circuit (Sample A).

If an identical IC can be purchased, the IC can be replaced with a new one and tested. By comparison, whether the original IC works normally or not, can be decided. The drive circuits for Sample A and Sample B are very similar. Although data of the IC in Sample B (1411HS) are not available, the general test method can be transferred. 


\section{Results and Evaluation}

\subsection{Analysis of Sample A Which Emits No Light}

The LED head circuit of spotlight $A$ starts to emit light at a DC bias of $15 \mathrm{~V}$, which corresponds to the minimum voltage across the LEDs in the IC manual. When the voltage increases, the current increases. When the current reaches its rated value of $35 \mathrm{~mA}$, the illuminating state is as shown in Figure 10a. The voltage value at this time is $16.5 \mathrm{~V}$ and all LED pairs are illuminating similarly brightly at $35 \mathrm{~mA}$. Therefore, it can be concluded that there is no problem with the LED head itself.

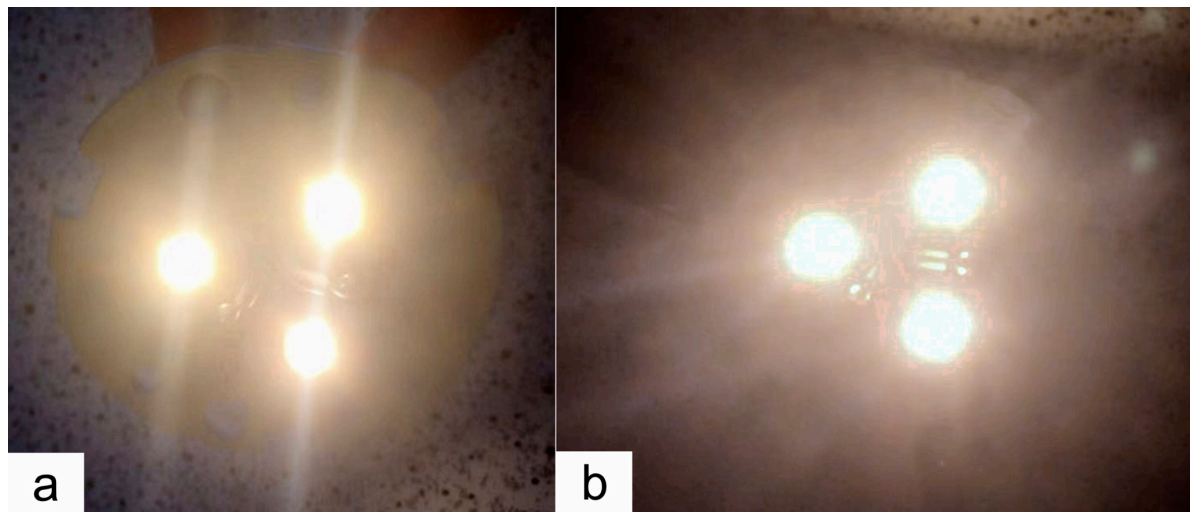

Figure 10. LED head of Sample A under current of $35 \mathrm{~mA}$ (a) and $200 \mathrm{~mA}(\mathbf{b})$.

Before testing the drive circuit, it is first necessary to draw a circuit schematic according to the actual drive circuit board and note the labeled values of the components in the circuit. The circuit diagram and labeled values of the drive circuit of sample $A$ are shown in Figure 11. Test results of all the components are shown in Table 4.

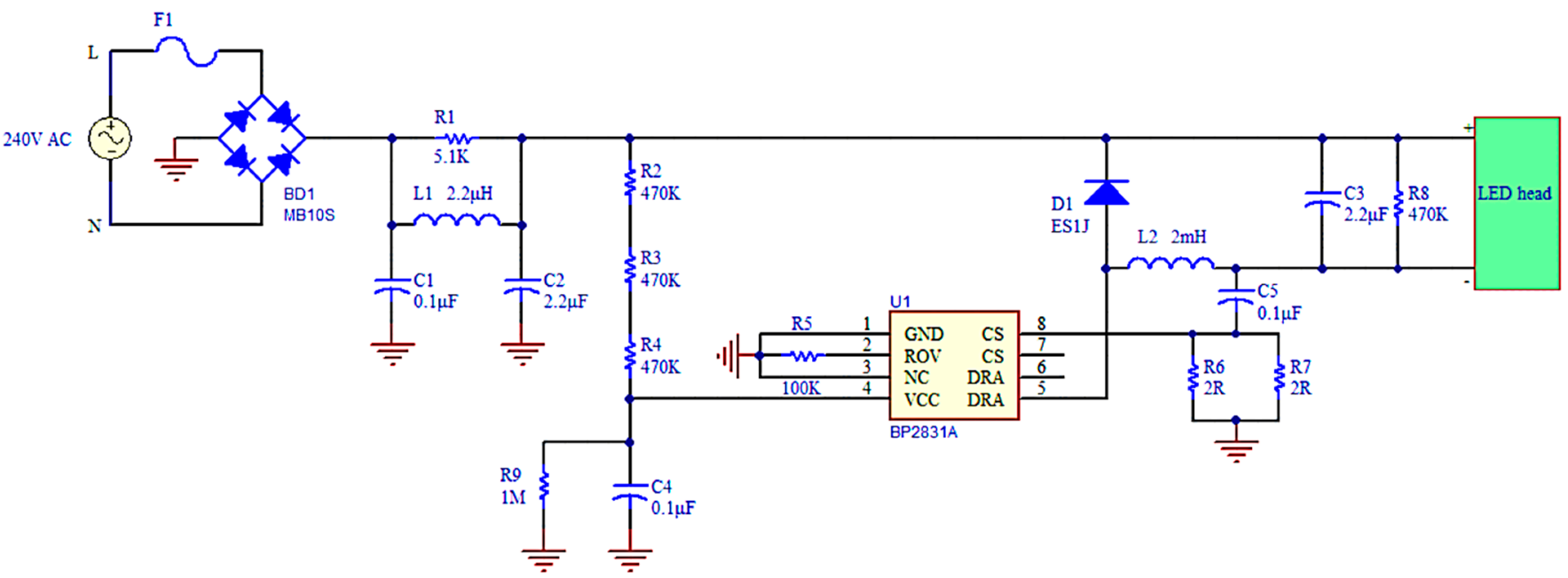

Figure 11. Diagram of the LED drive circuit with nominal values of component parameters (Sample A).

From Table 4 it is obvious that the measured test results of $R_{1}$ and $L_{1}$ are very different from the nominal values. $R_{2}, R_{8}$, and $C_{3}$ also have small differences. $R_{2}-R_{4}$ are used in series to reduce the voltage for use at the VCC pin. Since the total resistance of the resistors used for obtaining adequate VCC voltage is higher than $1 \mathrm{M} \Omega$ the small deviation of $R_{2}$ does not greatly affect the circuit. $R_{8}$ is a protective resistor at the output, and its resistance is much larger than the forward resistance of the LED head. Some errors in $R_{8}$ will not cause too much change in the output current. $C_{3}$ is an output filter stabilizing the output voltage. 
Again, a small decrease in the capacitance will not cause the LEDs to not work. In order to observe the influence of $L_{1}$ and $R_{1}$ faults on the circuit under 220-240 V AC, the rectification and filtering part of the circuit has been simulated in MATLAB (MathWorks Inc., Natick, MA, USA). If the nominal values are substituted into $L_{1}$ and $R_{1}$ of the simulation circuit, then the simulation results depicted in Figure 12 show that before the inductor and capacitor were damaged, the rectification and filter circuit would convert $240 \mathrm{~V}$ AC input to a stable 251 V DC voltage for the control circuit.

Table 4. Comparison of nominal and measured values of each component (Sample A).

\begin{tabular}{ccc}
\hline Component & Nominal Value & Measured Value \\
\hline$R_{1}$ & $5.1 \mathrm{k} \Omega$ & $5.3 \mathrm{M} \Omega$ \\
$R_{2}$ & $470 \mathrm{k} \Omega$ & $430.5 \mathrm{k} \Omega$ \\
$R_{3}$ & $470 \mathrm{k} \Omega$ & $471.2 \mathrm{k} \Omega$ \\
$R_{4}$ & $470 \mathrm{k} \Omega$ & $461.6 \mathrm{k} \Omega$ \\
$R_{5}$ & $100 \mathrm{k} \Omega$ & $99.5 \mathrm{k} \Omega$ \\
$R_{6}$ & $2 \Omega$ & $2.1 \Omega$ \\
$R_{7}$ & $2 \Omega$ & $2 \Omega$ \\
$R_{8}$ & $470 \mathrm{k} \Omega$ & $451.1 \mathrm{k} \Omega$ \\
$R_{9}$ & $1 \mathrm{M} \Omega$ & $1.1 \mathrm{M} \Omega$ \\
$C_{1}$ & $0.1 \mu \mathrm{F}$ \\
$C_{2}$ & $2.1 \mu \mathrm{F}$ \\
$C_{3}$ & $2.2 \mu \mathrm{F}$ & $1.79 \mu \mathrm{F}$ \\
$C_{4}$ & $2.2 \mu \mathrm{F}$ & $0.1 \mu \mathrm{F}$ \\
$C_{5}$ & $0.1 \mu \mathrm{F}$ \\
$L_{1}$ & $0.1 \mu \mathrm{F}$ & open \\
$L_{2}$ & $0.1 \mu \mathrm{F}$ & $2 \mathrm{mH}$ \\
$B D_{1}, D_{1}, F_{1}$ & $2.2 \mu \mathrm{H}$ & \\
\hline
\end{tabular}

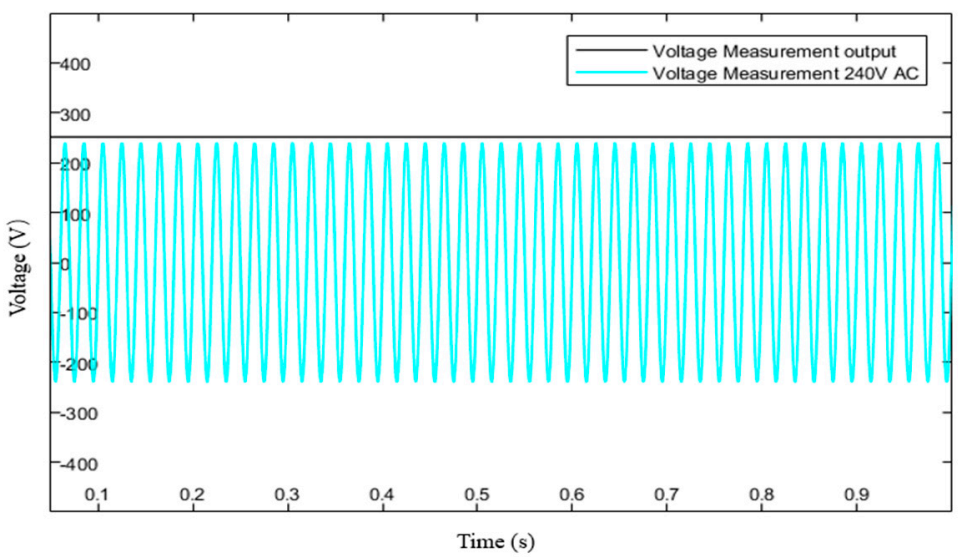

Figure 12. Simulated waveforms of the output of rectifier and filter circuit under $240 \mathrm{~V}$ AC for nominal $L_{1}$ and $R_{1}$ values (Sample A).

If a maximum input voltage of $265 \mathrm{~V}$ is substituted into the original circuit simulation, the simulated output voltage reaches $276 \mathrm{~V}$. When $L_{1}$ and $R_{1}$ are replaced with the actually measured values, the output of the filter circuit will generate a DC signal of up to approximately $800 \mathrm{~V}$ in a few seconds, as shown in Figure 13. Therefore, the damaged components cause the output voltage of the filter circuit to be much higher than the maximum allowed value for the circuit, resulting in the circuit not working. With a too large voltage supplied by the filter circuit, the voltage at the VCC pin of the IC will be higher than the clamp value, and the IC cannot turn on. 


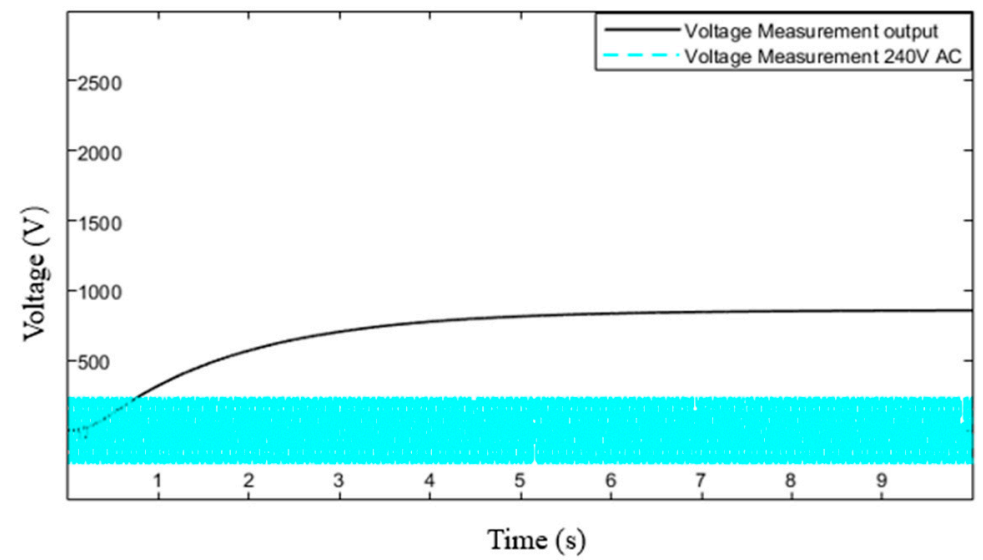

Figure 13. Simulated waveforms of the output of rectifier and filter circuit under $240 \mathrm{~V} \mathrm{AC}$ for measured $L_{1}$ and $R_{1}$ values (Sample B).

Although it has been determined here that the damage of the filter circuit causes the LEDs not to be damaged, it is also necessary to determine whether the IC itself has been damaged. According to the IC's manual, the turn-on voltage and the clamp voltage of VCC are $13.8 \mathrm{~V}$ and $16.8 \mathrm{~V}$, respectively. Therefore, if the VCC voltage is between $13.8 \mathrm{~V}$ and $16.8 \mathrm{~V}$, the MOSFET inside the IC will be turned on. In the experiment, the VCC voltage supplied is gradually increased from 0 to $20 \mathrm{~V}$ DC. On the drain side, the signal of the sensing circuit does appear when the VCC voltage is varied between $13.8 \mathrm{~V}$ and $16.8 \mathrm{~V}$. The measured output waveforms for three specific values of VCC (less than $13.8 \mathrm{~V}$, between $13.8 \mathrm{~V}$ and $16.8 \mathrm{~V}$ or greater than $16.8 \mathrm{~V}$, respectively) are plotted together in Figure 14.

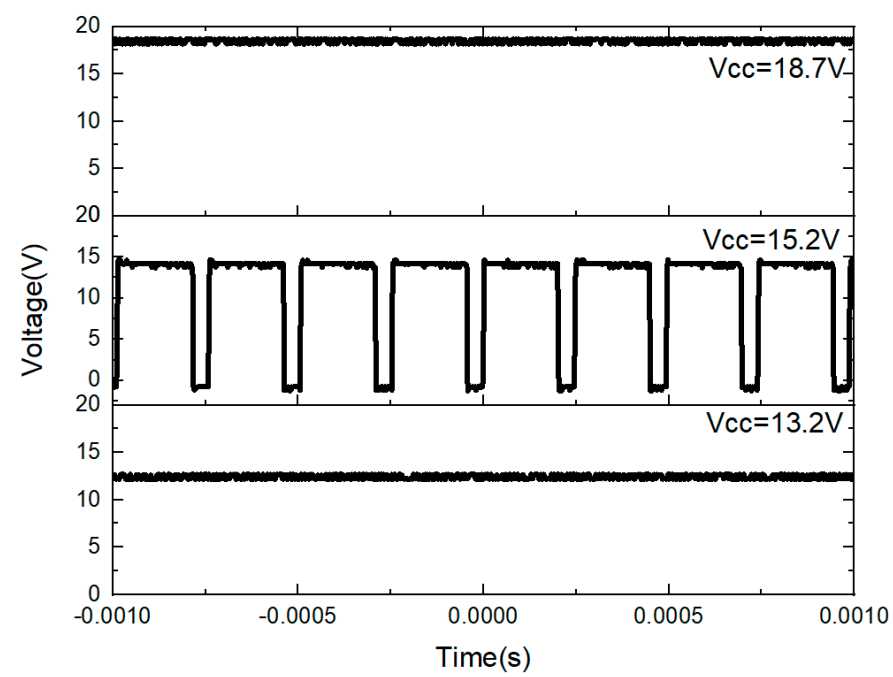

Figure 14. Measured waveforms at the drain pin under different VCC voltages (Sample A).

It can be seen from this figure that when VCC is less than the 'on'-value or greater than the clamp value, the output signal of the drain is VCC itself. Only in the intermediate working range, the signal of the sensing circuit is a modulated step function. Therefore, it can be determined that the MOSFET inside the IC does still work normally.

To test whether the whole sensing circuit inside the original IC still works, it is necessary to compare the original IC with the new IC in the test circuit. In the test circuit, the LEDs have been replaced with a $10 \Omega$ resistor, VCC is set to $15 \mathrm{~V}$, and $V_{\text {in }}$ also is $15 \mathrm{~V}$. The test results are shown in Figure 15. It can be seen from the figure that the output waveforms of the two test circuits are similar. The peak-to-peak voltage of $V_{\mathrm{CH} 2}-V_{\mathrm{CH} 1}$ measured by the two sets of tests are both $3.2 \mathrm{~V}$, which means that the two ICs, old and 
new, can provide the same voltage for the $10 \Omega$ resistor under the same conditions. We also checked in Figure $15 \mathrm{c}$ that for input voltages between $15 \mathrm{~V}$ and $25 \mathrm{~V}$ and load resistors of $5 \Omega, 10 \Omega$, and $15 \Omega$, both original and new IC behaved identically, from which we infer that the IC-controlled circuit can still maintain a constant output current if the input voltage and the output resistance are reasonably matched.
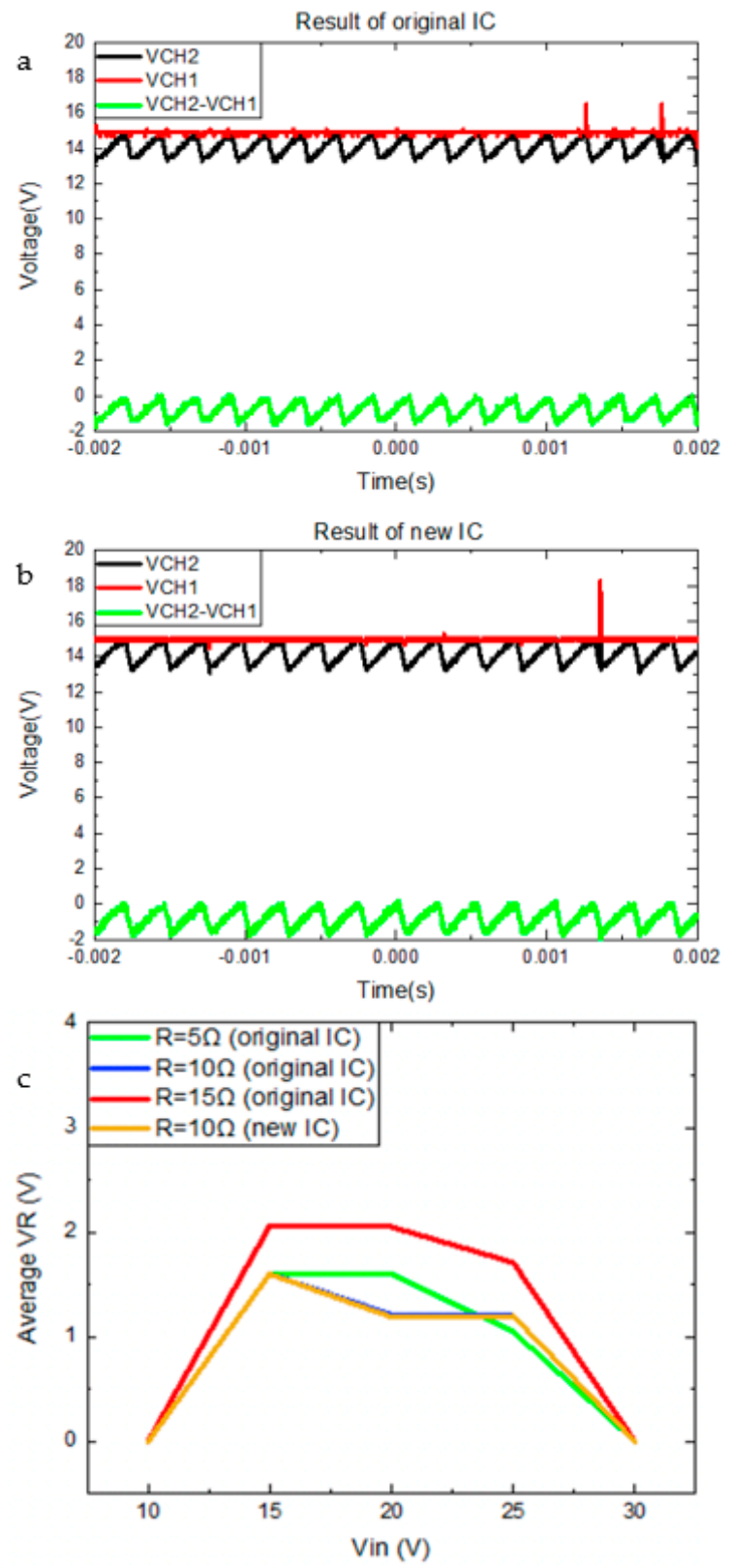

Figure 15. Measured waveforms of $V_{i n}\left(V_{C H 1}\right)$ and $-\left(V_{C H 2}-V_{C H 1}\right)$ of original (a) and new IC (b) with a $10 \Omega$ reference resistor (Sample A) and comparison of their output voltage for different reference resistors $(\mathbf{c})$.

In summary, the performance of the IC from the failed spotlight is identical to that of the newly purchased IC. Therefore, the sole cause of the device failure is the damaged individual components $L_{1}$ and $R_{1}$ in the filter circuit. The open circuit $L_{1}$ prevents the voltage across the rectifier from being converted into a reasonable DC voltage that could be used by the control circuit, thus causing spotlight failure for Sample A.

There are two possible reasons why the inductor $L_{1}$ could have been damaged. First, a high voltage surge of an external circuit may have caused the transient voltage near the 
inductor $L_{1}$ to be too large, disrupting it. Second, since the inductor is an energy storage component, the inductor was alternatingly charging and discharging when it was switched. The higher the switching frequency, the greater the voltage induced in the inductor. If the quality of an inductor is poor, it will be damaged after a certain period of use. As most of the circuits are nowadays equipped with anti-surge measures, the damage to the inductor is more likely to be due to the second reason. After the inductor has broken down, all the current in the circuit will have had to pass through $R_{1}$, leading to a high temperature of $R_{1}$, which will have caused $R_{1}$ to fail.

\subsection{Analysis of Sample B That Showed Strong Flicker}

The LEDs of sample $B$ are also illuminating when biased at $15 \mathrm{~V}$. The rated current of $44 \mathrm{~mA}$ is reached for $16.85 \mathrm{~V}$.

The drive circuit of Sample B is similar to that of Sample A. According to the actual circuit board, the schematic diagram of the LED drive circuit of Sample B is drawn in Figure 16. The test results of the components are listed in Table 5. Plots simulated of the voltage outputs of the rectifying and filter circuits for nominal and measured component values (not shown) differed by $12 \%$, which is unlikely to have caused the flicker.

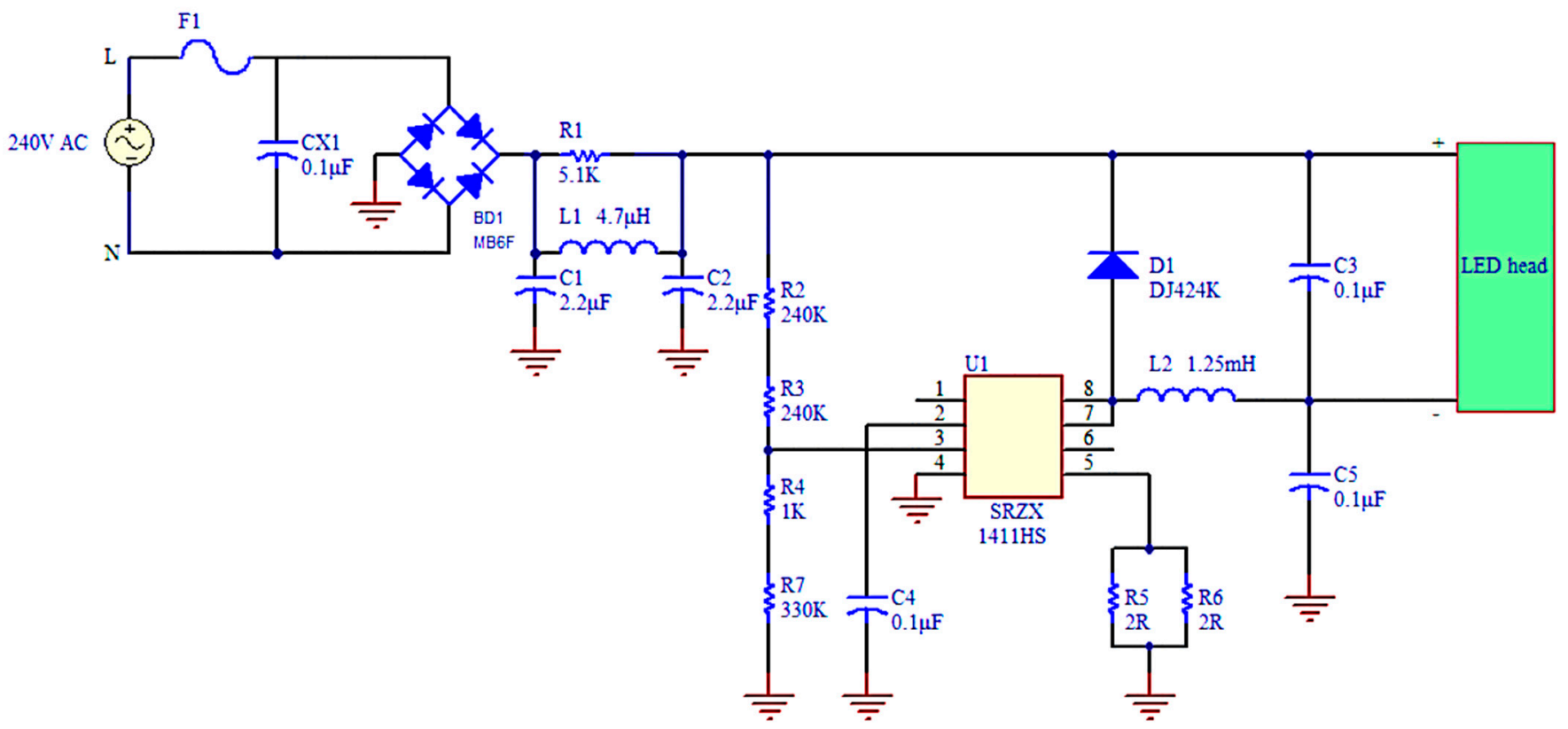

Figure 16. Schematic of LED drive circuit (Sample B).

There is no detailed information on IC 1411HS, which can no longer be purchased. When a voltage is applied to its presumed VCC pin 3, the drain signals expected at pins 7 and 8 remain 0 regardless of VCC, however, the identification of unlabeled input and output pins is ambiguous so that this IC cannot be tested in the same way as IC BP2381A.

From Table 5, there are problems with $C_{4}$ and in particular $C_{5} . C_{4}$ is a filter capacitor between the IC and ground. $C_{5}$ is connected to the output and ground. The function of these two capacitors is to eliminate electromagnetic interference, strengthen the interference rejection of the circuit, and keep the signal of the circuit stable. A failure of $C_{4}$ may cause the IC to not work properly and eventually cause flicker. A problem with $C_{5}$ may cause external electromagnetic wave signals to interfere with the output signal of the circuit, causing flicker. Capacitor failure in this LED drive circuit is likely to be temperature related as $C_{4}$ and $C_{5}$ are ceramic capacitors that are very susceptible to thermal changes. This LED drive circuit was packaged with silicone that may have reduced heat dissipation, which in turn could have affected discrete components. 
Table 5. Comparison of nominal and measured values of each component (Sample B).

\begin{tabular}{ccc}
\hline Component & Nominal Value & Measured Value \\
\hline$R_{1}$ & $5.1 \mathrm{k} \Omega$ & $5.1 \mathrm{k} \Omega$ \\
$R_{2}$ & $240 \mathrm{k} \Omega$ & $240.4 \mathrm{k} \Omega$ \\
$R_{3}$ & $240 \mathrm{k} \Omega$ & $239.2 \mathrm{k} \Omega$ \\
$R_{4}$ & $1 \mathrm{k} \Omega$ & $1 \mathrm{k} \Omega$ \\
$R_{5}$ & $2 \Omega$ & $2.07 \Omega$ \\
$R_{6}$ & $2 \Omega$ & $2.1 \Omega$ \\
$R_{7}$ & $330 \mathrm{k} \Omega$ & $327.5 \mathrm{k} \Omega$ \\
$C_{1}$ & $0.1 \mu \mathrm{F}$ & $0.1 \mu \mathrm{F}$ \\
$C_{1}$ & $2.2 \mu \mathrm{F}$ & $2.04 \mu \mathrm{F}$ \\
$C_{2}$ & $2.06 \mu \mathrm{F}$ \\
$C_{3}$ & $2.2 \mu \mathrm{F}$ & $0.1 \mu \mathrm{F}$ \\
$C_{4}$ & $0.1 \mu \mathrm{F}$ & $2.69 \mu \mathrm{F}$ \\
$C_{5}$ & $2.2 \mu \mathrm{F}$ & Open \\
$L_{1}$ & $0.1 \mu \mathrm{F}$ & $4.72 \mu \mathrm{H}$ \\
$L_{2}$ & $4.7 \mu \mathrm{H}$ & $1.24 \mathrm{mH}$ \\
$B D_{1}, D_{1}, F_{1}$ & $1.25 \mathrm{mH}$ & \\
\hline
\end{tabular}

\section{Discussion}

In this study, the internal components of two failed spotlight LED luminaires with GU10 form factor have been tested, and the failure mechanisms analyzed. Test circuits have been designed and tested separately for each part of the circuit. Combined with the simulation results, the circuits could be qualitatively analyzed for failed components. Due to a lack of a data sheet, the IC of Sample B was difficult to assess. According to the result, the causes of damage of the two LED spotlights are all related to electrical components within the LED drive circuits. Some aspects of the measurement processes are worth further discussion.

We could only identify one industrial study that, however, reported contradictory results [26]. On the one hand it predicted LED device failures were mostly due to defective solder interconnects (44\%), LEDs (30\%) and drive circuits $(28 \%)$, with half the devices reaching lifetimes of about $45,000 \mathrm{~h}$, but interestingly the conclusion reported on the other hand that 'the reliability of this system is clearly driver limited' without clear support data [26]. An experimental test of ten isolated drive circuits under increased temperature $\left(85^{\circ} \mathrm{C}\right)$ and relative humidity $(85 \%)$ conditions until failure [14] showed the most common drive circuit failure modes were related to polyester thin film capacitor leakage $(40 \%)$ and transistor short-circuits (30\%), and all drivers investigated failed within $3700 \mathrm{~h}$. Both studies seem to support our conclusion about the importance of premature catastrophic drive circuit failures.

\subsection{Output Current of Sample A}

Sample $A$ is described in the instruction manual. It is rated at $35 \mathrm{~mA}$. However, according to Equations (1) and (2), the resistances of $R_{5}$ and $R_{6}$ can be obtained, and the output current of the IC drive circuit should be $200 \mathrm{~mA}$. After testing, it was found that a drive current up to $200 \mathrm{~mA}$ does not damage the LED head, and its illumination under this much higher current is shown in Figure 10b. Although $C_{5}$ is connected between the output and the sensing end, the main function of $C_{5}$ is to filter the high-frequency signal at the output and maintain the stability of the output current. Therefore, it can be inferred that the output current of the IC does not match the rated current. In order for the output current of the drive circuit to match the LED head index value, the resistances of $R_{5}$ and $R_{6}$ would have to be increased correspondingly.

\subsection{Influence on the Circuit of Sample B If IC Is Damaged}

Since the drive circuit of Sample B is similar to the drive circuit of sample A, it can be inferred that the IC of Sample B has a function similar to that of the MOSFET and the 
sensing circuit in Sample A. If the filter circuit is normal, it can be inferred that the LED flicker is not caused by the VCC pin or the MOSFET. If VCC did not control the MOSFET properly, the LEDs would not flicker but instead would not emit any light at all. From our method for MOSFET testing, the reason why no waveform is seen at the output even if the MOSFET is turned on is because the applied VCC voltage (15 V to $40 \mathrm{~V})$ may not have reached the turn-on value. This would imply that the output voltage of the filter circuit in Sample B may be larger than for Sample A, and the step-down resistor is smaller in Sample B than in Sample A. A damaged sensing circuit may cause flicker. If the IC's sensing circuit is damaged, it will affect the $I_{\text {peak }}$ of the inductor. As can be seen from Equation (4), the $I_{\text {peak }}$ value is inversely proportional to the frequency, at fixed voltages and inductances. If $I_{\text {peak }}$ is too large, the output frequency will drop, causing the LEDs to visibly flicker.

\section{Conclusions and Outlook}

Although the use of LED lighting has become popular, there is still some lack of understanding of its lifetime. According to this study, a failure of the discrete components within the LED drive circuits is more likely than a damage of the LEDs themselves. Therefore, improving the quality of the LED drive circuit will be important to extend the lifetime of LED lighting.

In fact, the lifetime of LEDs may be very long [9], but if they cannot be matched with good quality drive circuits, the advantages of LEDs will not be fully utilized, and the higher prices of LED lighting compared to fluorescent or incandescent lighting are more difficult to justify. LED lamp manufacturers should thus focus on electrical components with improved reliability and temperature stability for their LED drive circuits.

While limited stability of the electric drive circuitry rather than the degradation of the LEDs themselves has already been identified as a potential problem several years ago [27] and efforts to improve these by avoiding semiconductor switches and electrolytic capacitors all together have been reported [28], we are not aware of experimental studies as detailed as this in investigating LED light failures of individual complete commercial devices.

Our findings are based on five GU10 luminaires investigated in total, two of which have been described here in detail, and in all cases the primary failures did not occur in the LEDs themselves although one LED pair (out of a total of 13 within those luminaires) had also subsequently failed, possibly as a result of a primary drive circuit issue. Two identical 3.7 W luminaires by alpha innovations had failed, one due to blown inductors in the rectifier, the other was flickering due to a mal-functioning LinkSwich LNK605 drive circuit. Another 4 W Philips lamp had failed because its NXP SSL2101 drive circuit did not produce any output any more.

There are two main limitations to this work. First, for safety reasons, it has not been possible to apply $230 \mathrm{~V} \mathrm{AC}$ to the primary side of the opened drive circuits that would have enabled us to directly test the illumination of the connected LEDs. Our study had thus to rely on circuit simulation and testing of individual components unsoldered from their boards, which itself includes the risk of damaging them. A meta-study of reports on failed components such as this may in the future improve statistics and enable a correlation with modelling of the ageing of such LED drive circuits under thermal stress. Another point has been the lack of technical data on the ICs of the drive circuits, such as here for Sample B. The library files for the two ICs are not available in design and simulation software packages, such as MATLAB, Multisim (NI, Austin, TX, USA), Proteus Design Suite (Labcenter Electronics Ltd., Grassington, North Yorkshire, UK), or Altium Designer (Altium Ltd., Chatswood, NSW, Australia). Hence, more comprehensive tests of LED lights may need the manufacturers to disclose technical information on parts.

Author Contributions: Experimental work, simulations, writing-original draft preparation: W.Z. Conceptualization, methodology, supervision, writing - review and editing: T.W. All authors have read and agreed to the published version of the manuscript.

Funding: This research received no external funding. 
Data Availability Statement: Not applicable.

Conflicts of Interest: The authors declare no conflict of interest.

\section{References}

1. Khan, N.; Abas, N. Comparative study of energy saving light sources. Renew. Sustain. Energy Rev. 2011, 15, 296-309. [CrossRef]

2. Mills, B.; Schleich, J. Household transitions to energy efficient lighting. Energy Econ. 2014, 46, 151-160. [CrossRef]

3. Round, H.J. A Note on Carborundum. In Semiconductor Devices: Pioneering Papers; Sze, S.M., Ed.; World Scientific: Singapore, 1991.

4. Holonyak, N.; Bevacqua, S.F. Coherent (visible) light emission from Ga( $\left.\mathrm{As}_{1-\mathrm{x}} \mathrm{P}_{\mathrm{x}}\right)$ junctions. Appl. Phys. Lett. 1962, 1, 82-83. [CrossRef]

5. Nakamura, S.; Mukai, T.; Senoh, M. Candela-class high-brightness InGaN/AlGaN double-heterostructure blue-light emitting diodes. Appl. Phys. Lett. 1994, 64, 1687-1689. [CrossRef]

6. Nishiura, S.; Tanabe, S.; Fujioka, K.; Fujimoto, Y. Properties of transparent Ce:YAG ceramic phosphors for white LED. Opt. Mater 2011, 33, 688-691. [CrossRef]

7. Zhang, C.; Heeger, A.J. Gallium nitride conjugated polymer hybrid light emitting diodes: Performance and lifetime. J. Appl. Phys. 1998, 83, 1579-1582. [CrossRef]

8. Sun, B.; Fan, X.J.; Ye, H.Y.; Fan, J.J.; Qian, C.; van Driel, W.; Zhang, G.Q. A novel lifetime prediction for integrated LED lamps by electronic-thermal simulation. Reliab. Eng. Syst. Saf. 2017, 163, 14-21. [CrossRef]

9. Humphreys, C.J. Solid-state lighting. MRS Bull. 2008, 33, 459-470. [CrossRef]

10. Lafont, U.; van Zeijl, H.; van der Zwaag, S. Increasing the reliability of solid state lighting systems via self-healing approaches: A review. Microelectron. Reliab. 2012, 52,71-89. [CrossRef]

11. Perpina, X.; Werkhoven, R.; Jakovenko, J.; Formanek, J.; Vellvehi, M.; Jorda, X.; Kunen, J.; Bancken, P.; Bolt, P.J. Design for reliability of solid state lighting systems. Microelectron. Reliab. 2012, 52, 2294-2300. [CrossRef]

12. Bergh, A.A.; Dean, P.J. Light-emitting diodes. Proc. IEEE 1972, 60, 156-223. [CrossRef]

13. Bakin, N.N.; Tuyev, V.I.; Yauk, E.F. LED lighting. In Proceedings of the 12th International Conference Seminar of Young Specialists on Micro/Nanotechnologies and Electron Devices (EDM), Erlagol, Altai, Russia, 30 June-4 July 2011; pp. 346-348.

14. Lall, P.; Sakalaukus, P.; Davis, L. Reliability and failure modes of solid-state lighting electrical drivers subjected to accelerated aging. IEEE Access 2015, 3, 531-542. [CrossRef]

15. Lall, P.; Zhang, H.; Davis, L. Failure mechanisms and color stability in light-emitting diodes during operation in high-temperature environments in presence of contamination. In Proceedings of the IEEE 65th Electronic Components and Technology Conf. (ECTC), San Diego, CA, USA, 26-29 May 2015; pp. 1624-1632.

16. Wang, X.X.; Jing, L.; Wang, Y.; Gao, Q.; Sun, Q. The influence of junction temperature variation of LED on the lifetime estimation during accelerated aging test. IEEE Access 2019, 7, 4773-4781. [CrossRef]

17. Lall, P.; Wei, J.; Davis, L. Solid state lighting life prediction using extended Kalman filter. In Proceedings of the ASME 2013 International Technical Conference and Exhibition on Packaging and Integration of Electronic and Photonic MicrosystemsInterPACK2013, Burlingame, CA, USA, 16-18 July 2013; article iPACK2013-73288. pp. 1-11.

18. Chen, Q.; Chen, Q.; Luo, X.B. Fast estimation of LED's accelerated lifetime by online test method. In Proceedings of the IEEE 64th Electronic Components and Technology Conference (ECTC), Lake Buena Vista, FL, USA, 27-30 May 2014; pp. $1992-1995$.

19. Qian, C.; Fan, J.J.; Fan, X.J.; Chernyakov, A.E.; Zhang, G.Q. Lumen and chromacity maintenance lifetime prediction for LED lamps using a spectral power distribution method. In Proceedings of the 12th International Forum on Solid State Lighting (SSL China), Shenzhen, China, 2-4 November 2015; pp. 67-70.

20. Pimputkar, S.; Speck, J.S.; Denbaars, S.P.; Nakamura, S. Prospects for LED lighting. Nat. Photonics 2009, 3, 179-181. [CrossRef]

21. Lee, Y.-S.; Chow, M.H.L. Diode rectifiers. In Power Electronics Handbook, 3rd ed.; Rashid, M.H., Ed.; Butterworth-Heinemann: Burlington, MA, USA, 2011; Chapter X; pp. 149-182.

22. Storr, W. Full Wave Rectifier. Available online: https:/ / www.electronics-tutorials.ws/diode/diode_6.html (accessed on 24 May 2021).

23. Williams, A.B.; Taylor, F.J. Electronic Filter Design Handbook, 4th ed.; McGraw-Hill: New York, NY, USA, 2006.

24. Non-Isolated Buck Offline LED Driver, Bright Power Semiconductor Co., Data Sheet BP2832A, Rev.1.0. Available online: http:/ / www.datasheet.es/PDF/864023/BP2832A-pdf.html (accessed on 27 May 2021).

25. Freitas, P.; Navarro, D.; O'Connor, I.; Billiot, G.; Lapuyade, H.; Begueret, J.B. Analog circuit design. In Planar Double-Gate Transistor: From Technology to Circuit; Amara, A., Rozeau, O., Eds.; Springer: Berlin, Germany, 2009; Chapter 5; pp. $105-136$.

26. Van Driel, W.; Evertz, F.; Zhang, G.Q. Towards a system level reliability approach for solid state lighting. J. Light Vis. Env. 2011, 35, 267-273. [CrossRef]

27. de Santi, C.; dal Lago, M.; Buffolo, M.; Monti, D.; Meneghini, M.; Meneghesso, G.; Zanoni, E. Failure causes and mechanisms of retrofit LED lamps. Microelectron. Reliab. 2015, 55, 1765-1769. [CrossRef]

28. Hui, S.Y.; Li, S.N.; Tao, X.H.; Chen, W.; Ng, W.M. A novel passive offline LED driver with long lifetime. IEEE Trans. Power Electron. 2010, 25, 2665-2672. [CrossRef] 